\title{
Ełnografia móvel: um estudo da mobilidade da informação na votação da PEC 171
}

MOBILE ETHNOGRAPHY: A STUDY OF MOBILITY OF INFORMATION IN THE VOTE FOR PEC 171

\section{Sandra Mara Garcia Henriques}

Doutora em Comunicação Social pelo Programa de Pós-Graduação em Comunicação Social da Pontifícia Universidade Católica do Rio Grande do Sul.

E-mail: henrisandra@gmail.com

\section{Liana Gross Furini}

Mestre em Comunicação Social pelo Programa de Pós-Graduação em Comunicação Social da Famecos/Pontifícia Universidade Católica do Rio Grande do Sul.

E-mail: lianagrossfurini@gmail.com

Recebido em 13 de setembro de 2016. Aprovado em 6 de dezembro de 2016.

\section{Resumo}

O empoderamento dos indivíduos na utilização de tecnologias móveis para publicar conteúdos constitui um espaço híbrido de fluxos informacionais. Para acompanhá-los, propomos como metodologia a etnografia móvel, que nos permite observar a mobilidade dos indivíduos e sua relação com os espaços e as informações. Acompanhamos a votação da PEC 171, em 2015, em duas mídias sociais através da ferramenta IFTTT e percebemos algumas diferenças: no Twitter, há uma relação maior com o conteúdo de um assunto; no Instagram, há uma relação mais forte com seu local.

Palavras-chave: Etnografia móvel. Mobilidade. Espaços híbridos.

\section{Abstract}

The empowerment of individuals in using mobile technologies for publishing content establishes a hybrid space of information flow. To follow this flow, we propose the mobile ethnography as methodology, which allows us to observe the mobility of individuals and their relationship with space and information. We chose to approach the vote for PEC 171 in 2015 on two social media through "If this than that" and noticed some differences: on Twitter, there is a stronger relationship with the content of a subject, and on Instagram there is a stronger relationship with its location.

Keywords: Mobile ethnography. Mobility. Hybrid spaces. 


\section{Introdução}

As tecnologias móveis nos proporcionaram uma amplitude da comunicação e informação, porque nos permitiram estar em plena mobilidade. A informação e as interações estão em constante movimento, transformando aspectos essenciais na forma como observamos os espaços urbanos e como passamos a produzir e compartilhar informações em tempo real.

O movimento e os rastros deixados na internet através das tecnologias móveis causam um grande impacto na relação entre os indivíduos e os processos comunicacionais e informais. Por tratarmos de espaços híbridos (territórios que unem o espaço físico e virtual), nossas técnicas de observação devem considerar ambos para compreendermos os registros deixados pelos movimentos tanto no espaço físico quanto no ciberespaço. Essas informações circulam por sites de redes sociais e aplicativos instalados em dispositivos móveis que utilizem tecnologias de geolocalização.

Os desafios dos estudos que abordam as questões relacionadas à mobilidade tecnológica vão além da busca de referenciais teóricos e observações de como se pode estudar o movimento de pessoas, ideias, objetos. No século XXI, em que a mobilidade é um dos focos de desenvolvimento tecnológico e cada vez mais influencia o contexto social, procuramos um método que leve em consideração a mobilidade da informação e que nos auxilie na busca de resultados que sirvam para demonstrar e confirmar os estudos realizados.

Este artigo parte de estudo teórico metodológico que se ampara em uma proposta de observar o mundo social, enfatizando que as práticas sociais envolvem algum tipo de movimento, seja de pessoas, ideias, informações ou objetos (BÜSCHER et al., 2011). Buscamos compreender as questões de propagação de informações a partir de pesquisa realizada nos dias 1 e 2 de julho de 2015, durante as votações da PEC 171, que propunha a redução da maioridade penal. Nossa proposta parte do estudo das informações postadas no Instagram e Twitter a partir da Câmara dos Deputados e arredores em Brasília (DF), bem como pesquisamos a hashtag "\#VotoContra171" proposta como "twitaço" nos dias de votação. Para tal, utilizaremos a etnografia móvel como método, pela necessidade que o objeto, em constante movimento, possui de mostrar os aspectos que envolvem as interações dos indivíduos entre si e com os locais estudados por meio da mobilidade tecnológica. É uma proposta de observar o contexto social pela perspectiva do movimento.

\section{Empoderamento do usuário e compartilhamento de conteúdo}

As tecnologias digitais, somadas à internet, permitiram que os usuários tivessem controle sobre o conteúdo, muito diferente do que acontece nas mídias tradicionais. $\mathrm{Na}$ 
internet, o usuário participa ativamente da produção e da circulação do conteúdo. Esse usuário, antes tido como mero receptor de conteúdo, passa a ter poder para escolher que tipo de conteúdo e informação quer consumir - situação que os aproxima de uma "cultura sob demanda", como aborda Tryon (2009).

Esse poder só aumentou com a difusão dos computadores pessoais na década de 1980 e sua constante melhoria para armazenar e processar conteúdos a partir da década seguinte. Para completar o cenário, a penetração da internet em banda larga, ao longo da primeira década do século XXI, criou condições para a aceitação de outras plataformas de conteúdo além de texto, como imagens, áudios e vídeos, o que permitiu uma maior diversificação de conteúdo. Esse público busca um conteúdo diferenciado e, mais importante, que possa ser acessado no dispositivo, ambiente e horário que mais o agradar.

A internet permite que um material seja criado e enviado uma vez só para todo o mundo, excluindo a necessidade de fazer cópia por cópia. Assim, o usuário só publica na internet, e as cópias vão sendo feitas enquanto o material vai sendo compartilhado, facilitando ainda mais a larga propagação de um conteúdo. Dalton e Leung (2013) apontam que qualquer pessoa com um computador em mãos e conectada à internet pode ter acesso a conteúdos de qualquer lugar do mundo, excluindo as restrições geográficas.

A popularização do computador foi peça-chave para que isso acontecesse. Mesmo tendo consciência da sua importância, entendemos que o computador, sozinho, não criou a cultura de compartilhamento. Acontece que, no momento em que esse computador é ligado a outros através de uma rede mundial, ele deixa de ser apenas um fazedor de cópias e passa a ser um dispositivo comunicacional (SCHÄFER, 2011). Para o autor, a cultura da participação tem tanto a ver com tecnologia quanto com pessoas.

O público internauta cada vez mais se torna responsável por criar parte do conteúdo disponível na rede, mas é importante lembrar que essa cultura da participação não existe apenas em função da tecnologia, mas também por vontade dos próprios usuários. Partindo desse pressuposto, Schäfer explica que a tecnologia é um fator importante para criar essa cultura, mas ela sozinha não é suficiente para fazer com que as pessoas compartilhem conteúdo umas com as outras. Segundo o autor, a "tecnologia é percebida como algo que, de uma forma mágica, permite que os usuários participem de uma produção coletiva, especialmente relacionado ao discurso de cultura participativa"2 (Ibid., p. 55, tradução nossa), o que na realidade não aconteceria se os usuários não tivessem motivos suficientes para participar.

2 Do original, "Technology is perceived as somehow magically enabling users to participate in collective production, especially in the discourse on participatory culture".

$110 \frac{\text { Comunicação \& Inovação, PPGCOM/USCS }}{\text { v. 18, n. 36 (108-121) jan-abr } 2017}$ 


\section{Tecnologias móveis e espaços híbridos}

A sociedade atual vive em plena mobilidade tecnológica, na qual o espaço híbrido - um misto do virtual do ciberespaço e dos locais físicos das cidades - é local utilizado cotidianamente para o indivíduo se informar e se comunicar com outras pessoas. Nesse ponto importante, trata-se a informação e seu contexto diante da mobilidade e dos dispositivos e como ela se desenvolve, criando seu próprio território dentro desse espaço híbrido: o território informacional. $\mathrm{O}$ espaço híbrido pode, de fato, ser observado como um grande território informacional, pois nele circulam infindáveis formas de comunicação e informação. O que se trata aqui é que atualmente vive-se um novo paradigma, ainda em fase de adaptação, que é o da mobilidade, apontando como novidade os estudos relacionados às formas de movimento proporcionadas pelas tecnologias móveis e seus impactos na informação e comunicação.

Juntamente com a emergência que as cidades e a população têm no acesso às redes wi-fi em busca da conexão, o uso do global positioning system (GPS) fomentou a criação de um novo território permeado de fluxos informacionais, resultante de uma intersecção entre ciberespaço e espaço urbano (LEMOS, 2007). Esses fluxos estão associados a um novo espaço híbrido, no qual a informação está associada e cada vez mais fomentada pelas pessoas que nele circulam. Pode-se dizer que os dispositivos móveis se tornaram mais conscientes de localização, e, com eles, os indivíduos passaram a deixar marcas nos espaços ao se movimentar e agregar informações a eles.

Segundo Virilio (1993), as novas tecnologias tendiam a abolir a dimensão física. Para ele, a "tecnologia desempenha um papel análogo ao criar novas interrupções de todas as formas, uma modificação do tempo próprio, [...] que traz consequências tanto para a organização do espaço urbano quanto para o espaço de arquitetura" (p. 65). Porém, o que se viu durante o desenvolvimento tecnológico foram os rastros deixados nos espaços sociais, agregando informação aos locais e objetos, deixando impressões que podem ser facilmente rastreadas. Objetos inteligentes passam a fazer parte do dia a dia, conectando pessoas e artefatos em qualquer tempo e lugar, tendo como base os dispositivos móveis.

Os rastros são deixados em espaços híbridos por meio da mobilidade que os dispositivos proporcionam. Uma impressão só é deixada porque uma ação naquele espaço foi realizada. Um dos importantes processos que permitem falar em rastros é a possibilidade de qualquer pessoa que possua um telefone celular deixar sua marca, sua informação sobre sua localização em espaços físicos pelo uso de sistemas de navegação por satélite. $\mathrm{O}$ uso desses artefatos, somado à amplitude das possibilidades de acesso à internet sem

fio, vem transformando os espaços. Esse sistema possibilita o reconhecimento do local e 
posicionamento do indivíduo ou de qualquer objeto (que possua um receptor) nos espaços físicos, servindo assim de forma precisa para identificar o movimento.

\section{Etnografia móvel como proposta para o estudo das mobilidades}

A mobilidade proporcionada pelas tecnologias móveis possibilita novas formas de movimento que podem se referir aos espaços e às relações sociais dos indivíduos e, com isso, permite que eles deem novos sentidos aos locais e às suas relações com outros indivíduos na formação dos grupos. Büscher e Urry (2009) apontam que o pesquisador passa a fazer parte do processo de pesquisa por meio de uma copresença, uma "sombra", se movendo junto ao objeto ou grupo pesquisado, munido de técnicas de observação para entender como se processa o movimento. A etnografia móvel é um método que traz consigo as características da etnografia clássica, mas que tem a peculiaridade de estudar o movimento dos indivíduos, não a comunidade estática; seus costumes e conceitos, além dos processos que levam ao movimento.

A metodologia proposta neste trabalho é uma adaptação do método clássico e do virtual de pesquisa etnográfica, que trata das mobilidades de uma justaposição de fatores locais e globais. É um processo de coleta de informações que utiliza as tecnologias móveis para mapear, acompanhar, registrar e descrever o processo, ampliando as práticas de observação, de descrição e de análise das dinâmicas interativas e comunicativas. O pesquisar encontra-se em plena mobilidade, assim como seu foco e os indivíduos estudados. Para Muskat et al. (2013), esse método etnográfico possibilita a coleta das informações diretas do indivíduo, pois ao mesmo tempo ele passa a relatar sua observação on-line (em algum site de rede social) no momento da experiência e no próprio local.

O foco da pesquisa etnográfica móvel, assim como todo o método fenomenológico etnográfico e suas adaptações, é o estudo dos fenômenos que envolvem os indivíduos em sociedade. Ela utiliza os recursos que permitem ao pesquisador registrar sua pesquisa acompanhando de forma móvel o grupo pesquisado. O fundamental está em compreender as experiências de mobilidade vivida pelos grupos e pelos indivíduos e quais seus reflexos na comunicação e interação social.

Por isso, a etnografia móvel está embasada na fenomenologia, pois interessam os contextos, os fenômenos que essa conjuntura representa na sociedade atual. Esse fator é de tal importância para as pesquisas em mobilidades que Jirón (2011, p. 37, tradução nossa) aponta: "a investigação sobre mobilidade precisa examinar as experiências de práticas 
de mobilidade, isto é, a maneira como as pessoas promulgam, experienciam e dão sentido às mobilidades na maneira de preparar, encarnar e construí-las diariamente"3.

Deve-se salientar que, diferentemente da pesquisa etnográfica clássica que prioriza um lugar, uma comunidade específica, a etnografia móvel passa a considerar vários lugares como fonte de pesquisa. Ela a complementa, não a exclui, e permite que a pesquisa e o pesquisador acompanhem, movam-se junto ao objeto pesquisado.

\section{IFTIT}

O IFTTT (sigla para "If this then that", que pode ser traduzida para "se isso, então aquilo") é um site que permite organizar dados com filtros programados a partir da escolha do usuário por meio de palavras-chave orientadas na busca em forma de "triggers" e "actions" que conectam diversas ferramentas digitais e aplicações móveis. A proposta principal é automatizar diferentes funções do smartphone, através de um roteiro (chamados de "receitas") com base em outros serviços da web (Google, Gmail, Instagram, Twitter, entre outros). Além disso, o serviço é um aliado na pesquisa etnográfica móvel, pois com ele é possível mapear as informações compartilhadas diretamente do local selecionado pelo pesquisador e também monitorar palavras-chave, como hashtags, selecionando e organizando o conteúdo para observação.

Nosso foco de pesquisa com o serviço IFTTT se refere a duas formas de observar a mobilidade na propagação de informações e conexões que se realizam em sites de redes sociais. Com o objetivo de entender esse processo, a pesquisa foi realizada em dois momentos políticos importantes para o país que, embora tratem da mesma questão, mostraram duas percepções ideológicas conflitantes. O primeiro momento da pesquisa foi a votação da Proposta de Emenda à Constituição no 171-A, de 1993, que "altera a redação do art. 228 da Constituição Federal" (BRASIL, [20--?]) (imputabilidade penal do maior de dezesseis anos) na Câmara dos Deputados, em Brasília (DF), que ocorreu no dia $1^{\circ}$ de julho de 2015 e foi rejeitada pela maioria dos deputados. O segundo momento refere-se ao dia seguinte, em que, por meio de sessão extraordinária, a emenda conhecida como PEC 171, que reduz a maioridade penal de 18 para 16 anos para crimes hediondos, homicídio doloso e lesão corporal seguida de morte, foi aprovada em primeiro turno.

A pesquisa foi mapeada a partir das publicações no Twitter e Instagram pelos indivíduos que, de alguma forma, participaram das mobilizações relativas à votação da PEC 171 (presencialmente ou não) durante os dois dias. Em primeiro lugar, observamos

3 Do original: "While classical ethnographers travelled to distant locations to participate in the target society's everyday life to gather data, modern ethnographers use modern technology to get under the skin of the target group". 
as publicações de indivíduos que estavam no local da votação, em Brasília (DF). Depois, monitoramos no Twitter a hashtag "\#VotoContra171", que nos revelou, entre tweets e retweets, a propagação desse conteúdo em plena mobilidade na rede social. Com a “\#VotoContra171” é possível ter acesso aos indivíduos que propagaram conteúdos a respeito da redução da maioridade penal.

\section{Twitter e Instagram: mobilidade e informação agregada ao local}

Como tratamos de espaços híbridos - territórios informacionais que unem o físico e o virtual -, nossas técnicas de observação devem trazer ambos para o estudo, de forma a compreender os registros deixados pelo movimento dos indivíduos. Para que as informações sejam compartilhadas, é necessário que esse processo se dê por meio de sites de redes sociais ou sites de geolocalização e aplicativos instalados em seus dispositivos móveis. Assim, para que a localização e informação sejam propagadas e compartilhadas, é necessária uma rede de outras pessoas que se conectem a esse mesmo ambiente.

Para desenvolvermos uma pesquisa que envolva como metodologia a etnografia móvel, faz-se necessário como ponto de partida uma pesquisa exploratória para que possamos compreender melhor o contexto atual. Neste artigo, tentamos compreender como os sites de redes sociais se adequaram aos processos de mobilidade e geolocalização, bem como perceber o fenômeno de sites de redes sociais que surgiram a partir de uma plataforma móvel, nos quais o espaço e o movimento completam a experiência.

\section{Observações do "\#VotoContra171" no Twitter}

Diante dos espaços híbridos, a informação está sempre em movimento. O que se destaca aqui é o aumento da capacidade de propagação por meio do compartilhamento dos indivíduos interagindo em rede. É o fluxo de ideias que promove conexões sociais e a propagação da informação, principalmente se os formatos forem de fácil compartilhamento. As tecnologias de comunicação sempre impressionaram pela velocidade com a qual levavam a informação às pessoas. Gabriel Tarde (2005) acreditava que não se poderia imaginar as transformações que os jornais causaram em relação ao espaço e ao tempo e na amplitude da conversação das pessoas. Para ele as questões da propagação de ideias e informações eram vitais para constituir as multidões.

As tecnologias móveis são grandes potencializadoras do Twitter. Com os telefones celulares de acesso à internet, é possível enviar e receber tweets onde quer que se 
esteja, em qualquer tempo e espaço. A atualização constante do Twitter sofre uma mudança com a conexão móvel: os relatos, a narração de conteúdos passa a ser atualizada em tempo real, e não mais experiências contadas quando se tem um computador disponível (PELLANDA, 2005).

Com o Twitter, destaca-se a mobilidade da informação, que se espalha rapidamente na rede. Diferente de redes sociais nativas móveis, o principal destaque quando se observa a propagação de hashtags é o movimento do conteúdo; a mobilidade dos indivíduos em espaços híbridos não é refletida de forma clara no conteúdo propagado. A hashtag “\#VotoContra171" é um bom exemplo disso. Por meio do mapeamento, observamos que após a chamada para o "twitaço" nos dois dias de votação, a hashtag foi utilizada 1.211 vezes entre tweets e retweets.

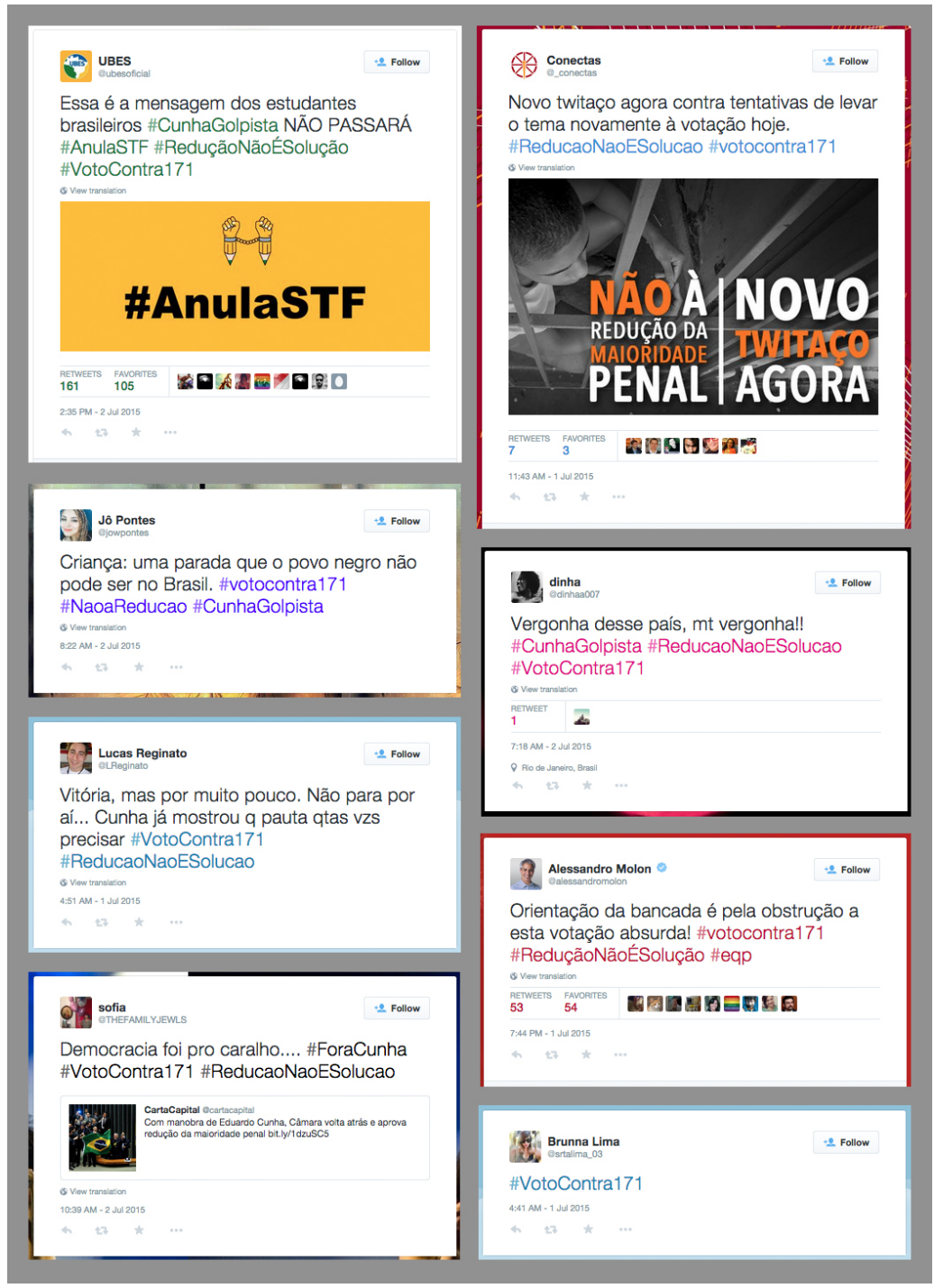

Figura 1. Tweets publicados nos dias 1 e 2 de julho com a hashtag “\#VotoContra171" Fonte: Twitter 
A possibilidade de comunicação no Twitter via dispositivos móveis permite que os indivíduos se tornem mais participativos no processo de disseminação de informação. Embora sempre associada à mobilidade, a localização do usuário só aparece publicamente quando ele escreve ou quando a associa em seu perfil. A característica global da mobilidade da informação é mais enfatizada pelo Twitter nesse caso, devido ao fato de o local e a valorização do espaço híbrido não estarem explícitas no conteúdo observado. Nesta pesquisa, notou-se que, embora a instantaneidade do Twitter possibilite o fluxo de informações e esse movimento esteja cada vez mais imbricado aos locais, as experiências com os espaços e a geolocalização possibilitada pela rede não permite, na maioria das vezes, que o local esteja representado em cada postagem.

Ainda no Twitter, pesquisamos as postagens feitas no local da votação durante o mesmo período - 1 e 2 de julho de 2015. Nesse período, em contraponto às 1.211 publicações que utilizaram a hashtag, apenas 12 tweets postados foram associados ao local. Destes, apenas dois tinham alguma relação com a votação da PEC 171; os demais tinham relação com o cotidiano dos indivíduos. Isso nos mostra que as publicações no Twitter têm uma relação muito maior com o conteúdo e muito menor com o local.

\section{Observações a partir do local no Instagram}

O Instagram é um aplicativo de rede móvel que permite ao usuário compartilhar fotografias e vídeos, aplicar filtros e compartilhá-los em sites de redes sociais. Criado em 2010, popularizou-se rapidamente pela facilidade na publicação e compartilhamento de conteúdo, chegando a mais de 100 milhões de usuários em dois anos. A geolocalização faz parte do Instagram desde 2012, quando um mapa foi inserido para que as pessoas pudessem associar suas publicações aos locais - desde então, antes de publicar um conteúdo, basta apenas adicionar sua localização no mapa.

Por ser uma mídia social nativa móvel, desenvolvida para o uso dos indivíduos em mobilidade, foi possível observar que, no Instagram, a possibilidade de curtir e comentar as fotos e vídeos de outras pessoas o transforma em um aplicativo de rede social associado ao contexto local que se propaga em nível global, pois, além da estética fotográfica - que atrai outros indivíduos -, há a possibilidade de compartilhá-la em outros sites de rede social, como o Facebook e o Twitter. Além disso, as hashtags são utilizadas como indexadores, potencializando o conteúdo e as imagens publicadas e ampliando a conexão entre os usuários.

Com a possibilidade de mapear as publicações a partir de qualquer espaço físico das cidades por meio do IFTTT, nossa intenção foi verificar se havia convergência nas 
informações compartilhadas pelos indivíduos no Instagram a partir do local e no momento da votação. Durante os dois dias, 104 fotos relacionadas à votação da PEC 171 foram publicadas a partir do local da sessão em Brasília (DF).

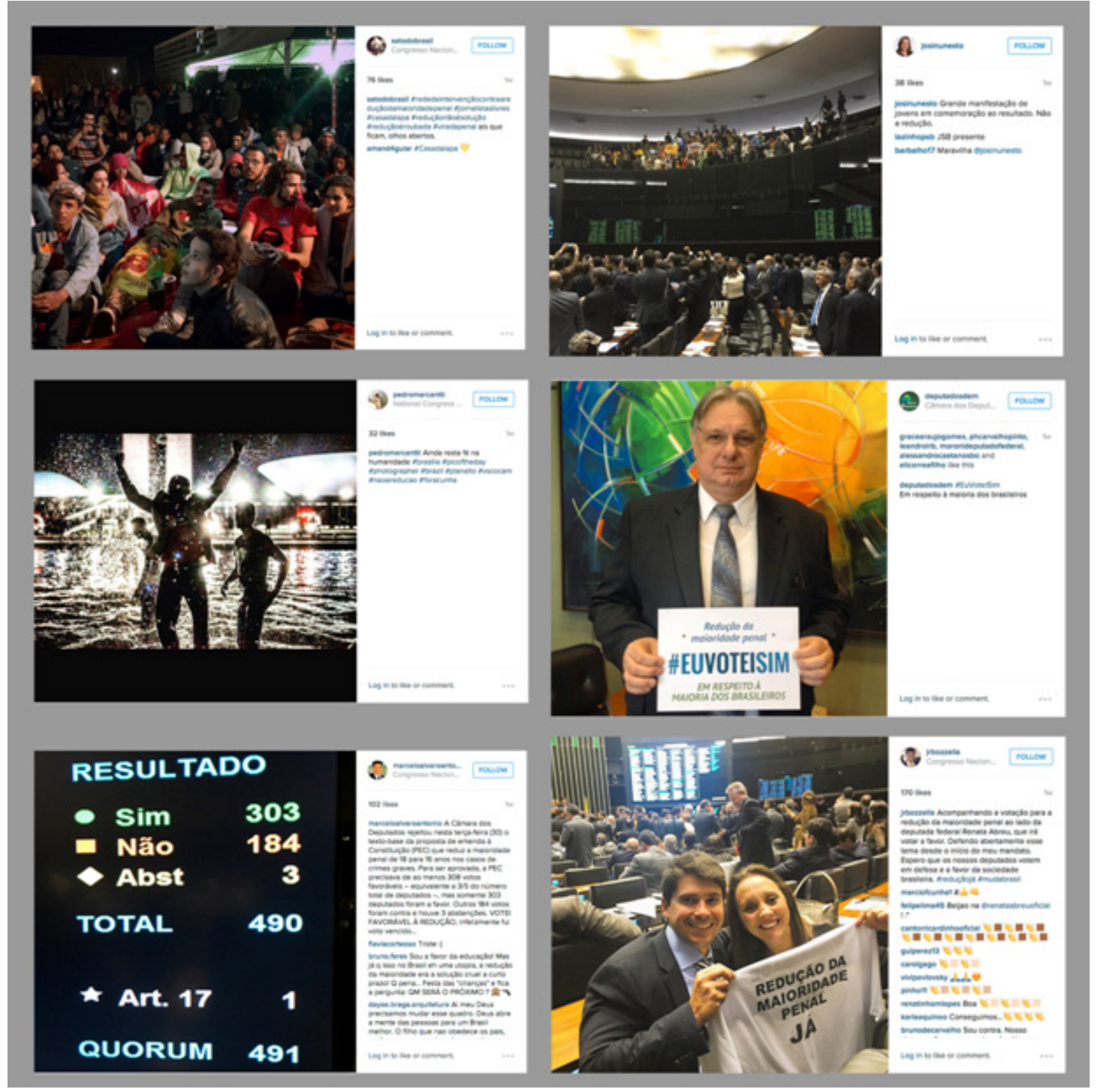

Figura 2. Publicações dos dias 1 e 2 de julho durante a votação da PEC 171

Fonte: Instagram

A pesquisa com o serviço IFTTT nos permite observar a mobilidade e o significado que os indivíduos atribuíram ao local e ao conteúdo aos quais estavam agregados naquele período. O que ocorreu nesse processo foi uma associação entre conteúdo, pessoas e locais, atribuindo um sentimento de pertença ao publicar e compartilhar uma informação. A propagação a partir do local onde está acontecendo o fato é uma forma diferenciada de empoderar os indivíduos que vai além da publicação em rede, como vemos em outras redes sociais. 
É possível observar que há uma associação entre a publicação e o local, gerando um novo significado que dá sentido e remete à construção de um espaço social que une a propagabilidade dos espaços virtuais à localidade e significação dos locais das cidades. Esse ponto amplifica o empoderamento dos indivíduos e a construção de novos espaços sociais.

A conexão em rede parte do conteúdo e de sua relação direta ao local, o que produz significados para e pelos indivíduos, pois registram-se no espaço os rastros deixados por cada um que passa e que, por meio de dispositivos móveis e do espaço híbrido, agregam sentido ao referido lugar - lugar que permanecerá para que outros que ali passarão possam ter acesso a essa informação como rastros associados ao local. Assim, as imagens e as hashtags são pontos de conexão que possibilitam entender os efeitos da mobilidade informacional a partir do conteúdo somado ao local.

As hashtags, no caso do Instagram, evidenciam os rastros deixados pelos indivíduos naqueles espaços híbridos e permanecem para que outros tenham acesso, assim como as imagens publicadas. Esses rastros permeiam um espaço, territorializado pela informação, mas que precisa de contexto para que esse processo se efetive. Como veremos no gráfico a seguir, diversas hashtags foram associadas à votação e ao local ${ }^{4}$.

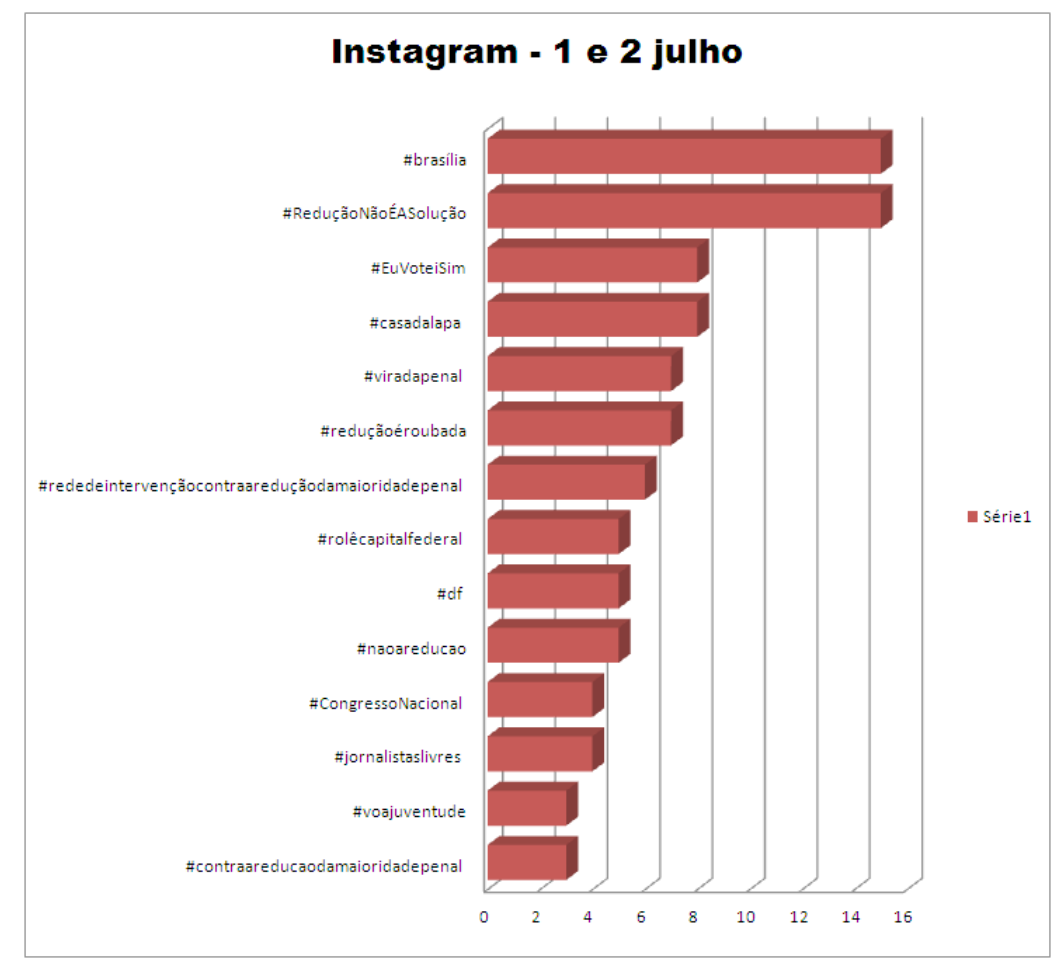

Gráfico 1. Hashtags utilizadas entre os dias 1 e 2 de julho

Fonte: Elaborada pelas autoras

4 Foram 104 postagens relacionadas à votação da PEC 171, ressaltamos neste gráfico apenas aquelas reproduzidas mais de 3 vezes. As demais foram utilizadas apenas uma vez.

$118 \frac{\text { Comunicação \& Inovação, PPGCOM/USCS }}{\text { v. 18, n. 36 (108-121) jan-abr } 2017}$ 
O que se destaca nesse contexto é que a "\#VotoContra171", uma das hashtags mais utilizadas, não foi observada em nenhuma postagem do Instagram realizada no local das votações. Isso nos faz entender que há uma diferença na propagação e apropriação dos contextos relacionados ao mesmo conteúdo. Embora o enfoque tenha sido o mesmo nos dias apurados, a diferenciação entre uma rede social nativa móvel e outra que ainda se adapta à geolocalização é bastante notável. O que uniu, além do contexto, os usuários no Twitter foi a convocação para uma mobilização independente de onde o indivíduo estivesse; o local nesse caso pouco importou para disseminar o conteúdo. Já no Instagram, a geolocalização é observada nas imagens divulgadas diretamente do local das votações; a mobilidade aqui é referenciada não somente ao local, mas também aos conteúdos produzidos e propagados, mostrando que não houve uma unidade na propagação de hashtags únicas conectadas ao contexto. Diversas hashtags foram utilizadas para compartilhar informações que envolviam não apenas o contexto, mas o local e o momento em que o fato estava ocorrendo.

Essa propagabilidade gera um movimento, o que nos revela outra fase da participação dos indivíduos na distribuição e produção de informação. O que se pode observar com esse novo contexto é que se vive um modelo híbrido no qual a possibilidade de compartilhar e circular informação leva o indivíduo a um processo social mais participativo de cultura.

\section{Considerações finais}

Há uma diferença entre as mídias sociais analisadas que é fundamental para os estudos das mobilidades: no Twitter, pode-se observar de forma mais abrangente a mobilidade da informação, a propagação dos conteúdos de forma ampla. Conexões com os espaços se dão de forma mais global do que local. O Twitter segue a lógica de rede de amplo compartilhamento, e seu ponto forte é o uso ativista da hashtag, promovendo "twitaços" sobre determinados assuntos, como observamos com a "\#VotoContra171". Ou seja, serve como rede fundamental para o "ativismo de sofá", importante forma de empoderamento, mas que ainda deixa a desejar quando se refere à informação em espaços híbridos. Essa questão é importante e retrata que a geolocalização ainda é um problema para a rede social, pois, atualmente, seus recursos de localização ainda são limitados ao indivíduo quando ele identifica, escreve onde está, ou quando lista a localização em sua biografia. Vimos esse ponto durante a pesquisa no Twitter nos dias e local de votação, que mostrou que apenas 12 tweets foram realizados a partir daquele espaço e somente dois tratavam da votação da PEC 171. As pessoas foram mais ativas na manifestação com relação à informação do que com relação ao espaço. 
Já no Instagram, o que se observa é a mobilidade da informação agregada ao local, sendo um ponto fundamental para estudar as interações em espaços híbridos. Várias hashtags postadas tiveram relação com o local, como "\#Brasília”, “\#df”, “\#congressonacional", "\#rolecapitalfederal”, mostrando que o espaço físico é importante para a postagem, que faz parte dela; além de associar a imagem ao local, a hashtag o ressalta ainda mais. Ao todo, 557 pessoas publicaram fotos no Instagram no local da manifestação nos dias 1 e 2 de julho de 2015. Destas, 104 eram referentes à votação da redução da maioridade penal.

Enquanto o Twitter chamou os usuários para a mobilização com a hashtag "\#VotoContra171", o Instagram mostrou a mobilização no local do fato por meio de imagens e diversas outras hashtags. Esses diferentes tipos de observação são identificados por meio da proposta de um procedimento metodológico para estudar mobilidades. Com a etnografia móvel, apontamos novos parâmetros a serem considerados nos estudos da mobilidade tecnológica e sua apropriação durante manifestações sociais, bem como no cotidiano dos indivíduos a partir da pesquisa em espaços híbridos.

A etnografia móvel realizada nos permite compreender que, nesse caso, a manifestação não teve exclusivamente relação com o local - as pessoas participaram pelo Twitter de casa, do trabalho, de qualquer lugar, e as formas de manifestação vão além de estar no local e fazer parte fisicamente do movimento. É uma forma de empoderamento, em que cada um participa como quiser, seja indo até o local, seja usando uma hashtag proposta para a manifestação ou usando uma hashtag qualquer relacionada ao movimento. No Twitter, a informação propagada virtualmente constituiu uma unidade no discurso, ao contrário do Instagram, pois neste as hashtags foram dispersas e com menor amplitude, porém foram deixados rastros de informação e imagem sobre a manifestação, que foram agregados ao local da votação e permanecerão nesse espaço para que posteriormente outros indivíduos tenham acesso.

\section{Referências}

BRASIL. Ministério Público do Estado do Rio Grande do Sul. Proposta de Emenda à Constituição $n^{\circ} 171$, de 1993. Altera a redação do artigo 228 da Constituição Federal. [20--?]. Disponível em: <http:// bit.ly/2kryKvM>. Acesso em: 3 fev. 2017.

BÜSCHER, M. et al. (Orgs.). Mobile methods. New York: Routledge, 2011.

BÜSCHER, M.; URRY, J. Mobile methods and the empirical. European Journal of Social Theory, [S.1.], v. 12, n. 1, p. 99-116, fev. 2009.

DALTON, J. T.; LEUNG, T. C. Strategic decision-making in Hollywood release gaps. MPRA - Munich Personal RePEc Archive, Munich, n. 5.2439, dez. 2013. Disponível em: < http://bit.ly/2kO5Wyy>. Acesso em: 3 fev. 2017.

$120 \frac{\text { Comunicação \& Inovação, PPGCOM/USCS }}{\text { v. 18, n. 36 (108-121) jan-abr } 2017}$ 
JIRÓN, P. On becoming "la sombra/the shadow". In: BÜSCHER, M. et al. (Orgs.). Mobile methods. New York: Routledge, 2011.

LEMOS, A. Cidade e mobilidade. Telefones celulares, funções pós-massivas e territórios informacionais. Matrizes, São Paulo, v. 1, n. 1, p. 121-137, 2007.

MUSKAT, M. et al. Generation Y: evaluating services experiences through mobile ethnography. Tourism Review, Bingley, v. 68, n. 3, p. 55-71, 2013. Disponível em: <http://bit.ly/2kOeupn>. Acesso em: 3 fev. 2017.

PELLANDA, E. C. Internet móvel: novas relações na cibercultura derivadas da mobilidade na comunicação. 2005. Tese (Doutorado em Comunicação Social) - Pontifícia Universidade Católica do Rio Grande do Sul, Porto Alegre, 2005.

SCHÄFER, M. T. Bastard culture!: how user participation transforms cultural production. Amsterdam: Amsterdam University Press, 2011.

TARDE, G. A opinião e as massas. São Paulo: Martins Fontes, 2005.

TRYON, C. Reinventing cinema: movies in the age of media convergence. New Brunswick: Rutgers University Press, 2009.

VIRILIO, P. O espaço crítico. Rio de Janeiro: Editora 34, 1993. 